\title{
Is routine urine testing in outpatient clinics useful?
}

\section{A G Morgan}

Renal Unit, City Hospital, Nottingham NG5 1PB

A G Morgan, FRCP, consultant physician

New diagnoses made after investigation of unexpected abnormal results of urine testing

\begin{tabular}{lr}
\hline Diagnosis & No \\
\hline \multicolumn{1}{c}{$\quad$ Systemic } & \\
Diabetes mellitus & 8 \\
Myelomatosis & 1 \\
Bacterial endocarditis & 1 \\
Hypertensive nephrosclerosis & 1 \\
Polycystic renal disease & 1 \\
Exercise haematuria & 1 \\
\multicolumn{1}{c}{$\quad$ Urological } \\
Prostatism and obstruction & \\
Urinary infection & 6 \\
Calculi & 3 \\
Carcinoma of bladder & 2 \\
& 1 \\
\multicolumn{1}{c}{ Gynaecological } & \\
Menstruation & \\
Pelvic carcinoma & 1 \\
Vaginal polyp & 1 \\
\hline Total & 30
\end{tabular}

.
normal results (mean age 60.8 (SD 15.4) years $v 49.5$ $(18.6)$ for male patients ( $t$ test, $\mathrm{p}<0.001$ ) and 53.2 $(18 \cdot 8) v 43.6(18 \cdot 8)$ for female patients $(\mathrm{p}<0.001))$. Overall, abnormal results were more common in male $(7 \cdot 8 \% ; 171 / 2184)$ than female $(3 \cdot 1 \% ; 116 / 3702)$ patients $\left(\chi^{2}=64 \cdot 3, \mathrm{p}<0.001\right)$, but no such difference was found in patients attending medical and surgical clinics, where the age distribution in the sexes was similar $\left(\chi^{2}=3 \cdot 7, p>0.5\right)$. The prevalence of abnormal
In many hospitals the urine of outpatients is routin tested, but whether this is a useful way of discovering asymptomatic disease is uncertain. I therefore carried

\section{Patients, methods, and results}

For 25 weeks records were kept of all routine urine tests on new patients seen in adult clinics (other than antenatal) at this hospital. The tests were performed by nurses with dipsticks (BM-Test-5L; Boehringer, Mannheim); the urine sample had been collected by the patient at home or provided on arrival. The graded results for protein, blood, and glucose were recorded in the hospital notes before the patient was seen by a doctor. Hospital notes for patients with abnormal results were reviewed at least six months after the initial attendance and a judgment made as to whether the abnormality might have been expected from information already available at the first visit. For unexpected results evidence of an attempt to discover

Information on 2184 male and 3702 female patients aged 1-95 was recorded. They attended medical (1891 patients), gynaecological (1808), surgical (1240), urological (726), and geriatric (221) clinics. In 287 patients $(4.9 \%)$ protein, glucose, or blood was detected abnormal results were older than those who had analysis of urine. the cause was sought and the eventual diagnosis noted. to some degree $(+,++$, or +++$)$. Patients who had

results differed strikingly between clinics $\left(\chi^{2}=297\right.$, $\mathrm{p}<0.001$ ) largely because it was very low in gynaecological patients $(0.6 \% ; 11 / 1808)$.

In 166 of the 287 patients with positive findings the result could have been expected from information already available when the patient was first seen. Among the 121 others further investigations had been carried out in only 60 . In 30 patients $(0.5 \%$ of all those tested) new diagnoses had been made (table).

\section{Comment}

In what seems to be the only other report of urine screening in hospital outpatients Fraser et al tested 2600 people of all ages not only for protein, glucose, and blood but also for $\mathrm{pH}$, ketones, bilirubin, urobilinogen, and nitrite and found that $7 \%$ had abnormal results. ${ }^{1}$ Webster reported protein and blood in $2 \%$ of 763 well patients referred specifically for screening. ${ }^{2}$ The current survey showed that dipstick urine testing used in a manner similar to that used in many British hospitals showed protein, glucose, or blood, alone or in combination, in about $5 \%$ of unselected outpatients. In just under half of these patients the abnormalities might not have come to light if routine screening had not been used.

That asymptomatic abnormalities in the urine can indicate serious and potentially treatable disease may not be sufficiently widely appreciated. Failure of doctors either to notice or to act on abnormal results was common as has been noted previously. ${ }^{23}$ If all abnormalities had been investigated the total number of new diagnoses found during the survey period might have increased from 30 to 48 . As with any routine procedure, urine analysis can be justified only if action is taken on the basis of the results it brings to light.

I thank Mrs J Poll for her help, my colleagues for their permission to survey their clinics, and the Nottingham and Nottinghamshire Kidney Fund for financial support. 1 Fraser CG, Smith BC, Peake MJ. Effectiveness of an outpatient urine screening
program. Clin Chem 1977;23:2216-8.
2 Webster IW. A preliminary report on the operation of a multiple screening
centre in Sydney. Med J Aust 1972;2:488-92.
3 Ritchie CD, Bevan EA, Collier SJ. Importance of occult haematuria found at
screening. BrMed I 1986;292:681-3.

(Accepted 28 fuly 1988)

\section{BCG immunisation of infants by percutaneous multiple puncture}

\section{B Cundall, D J Ashelford, S B Pearson}

\section{Department of Paediatrics and Child Health, St James's University Hospital, Leeds D B Cundall, MRCP, tutor}

Leeds Chest Clinic, Leeds LS1 6PH

D J Ashelford, MB, clinical assistant

S B Pearson, DPHIL, consultant physician

Correspondence to: Dr Pearson.
Immunisation of infants with BCG provides effective protection against tuberculosis in childhood, ${ }^{12}$ but the standard intradermal method is difficult in young babies. We assessed the safety, efficacy, and ease of administration of a percutaneous multiple puncture method.

\section{Patients, methods, and results}

We allocated 214 consecutive babies less than 8 weeks old referred to the chest clinic for immunisation with BCG alternately, with parental consent, to the percutaneous or intradermal method. None of the infants was known to have been in contact with a patient with active tuberculosis. Immunisation was done by one of three doctors.

Modified Heaf guns with 20 needles set to penetrate to a depth of $1 \mathrm{~mm}$ (East Health Care, Oxford) were used to administer percutaneous vaccine (Evans Medical) through the skin overlying the left deltoid muscle. Gun heads were sterilised between immunisations by flaming for one minute. Injections of $0.05 \mathrm{ml}$ intradermal vaccine were given into the dermis overlying the left deltoid muscle with a syringe fitted with a 24 gauge short bevelled needle. Doctors recorded the ease of administration of the vaccine and any bleeding that occurred.

The infants were Heaf tested four months after immunisation. A doctor who was unaware of the method of immunisation read the test three to seven days later, inspected the site of the injection, and asked about complications and other immunisations.

Fourteen babies were lost to follow up, leaving 200 in the study ( 107 boys, 93 girls). All of the babies had been born in the United Kingdom; their ethnic origin was Asian (from the Indian subcontinent), 157; white European, 17; South East Asian, nine; Arabian, five; African, four; and others, eight. Mean (SD) age was 47 (10) days at immunisation and 172 (12) days when the Heaf test was read. Positive Heaf reactions were found in 141 babies ( 130 grade 1 and 11 grade 2).

One hundred babies were immunised by each 
method. Babies immunised by the different methods and different doctors did not differ significantly in demographic variables, weight, method of feeding, or the number and timing of other routine immunisations. The intradermal method was recorded as difficult on 36 occasions and very difficult on four; the percutaneous method was recorded as difficult once. A small amount of bleeding at immunisation was noted in 14 babies from each group. Ulceration was reported only in those who had had intradermal immunisation (five cases). None of the babies developed lymphadenopathy. A scar was visible in 95 of those immunised intradermally and 63 of these immunised percutaneously $\left(\chi^{2}=30 \cdot 6, \mathrm{df}=1, \mathrm{p}<0 \cdot 05\right)$. The proportion of positive results on Heaf testing was similar among the different ethnic groups - for example, $69 \%$ of Asians $(108 / 157)$ and $70 \%$ of white Europeans (12/17). The table shows the number of positive results according to the method of immunisation and the doctor giving the immunisation. The two methods gave similar rates of conversion. The rate of conversion differed significantly among doctors when the intradermal method was

Results of Heaf tests according to doctor who gave immunisation and method of immunisation. Values are expressed as number of positive results/number of babies immunised (percentage)

\begin{tabular}{|c|c|c|c|c|}
\hline & \multicolumn{3}{|c|}{ Doctor who gave immunisation } & \multirow[b]{2}{*}{ Total } \\
\hline & A & B & $\mathrm{C}$ & \\
\hline $\begin{array}{l}\text { Percutaneous } \\
\text { Intradermal }^{\star}\end{array}$ & $\begin{array}{l}26 / 36(72) \\
26 / 41(63)\end{array}$ & $\begin{array}{l}27 / 42(64) \\
28 / 40(70)\end{array}$ & $\begin{array}{l}15 / 22(68) \\
19 / 19(100)\end{array}$ & $\begin{array}{l}68 \\
73\end{array}$ \\
\hline
\end{tabular}

$\star \chi^{2}=9 \cdot 02, \mathrm{df}=2, \mathrm{p}<0 \cdot 02$ used but not when the percutaneous method was used. Babies with negative results on Heaf testing will be tested again when they are 1 year old.

\section{Comment}

The percutaneous method of immunising infants with BCG is safe and effective, ${ }^{3}$ although it is rarely used (unpublished data). We have reported a considerable number of cases of tuberculosis in unimmunised children. ${ }^{4}$ We currently immunise all babies of Asian origin but only white babies and children who have been in contact with patients with tuberculosis before they start school, and perhaps this policy needs reappraisal.

We recommend the use of the percutaneous method, particularly if large numbers of infants are to be immunised. This method is less dependent than the intradermal method on the doctor giving the immunisation, produces less scarring, and has a similar rate of conversion.

We thank the parents, health visitors, and staff of the chest clinic for help with this study.

1 Curtis HM, Leck I, Bamford FN. Incidence of childhood tuberculosis afte neonatal BCG vaccination. Lancet 1984;i:145-8.

2 Packe GE, Innes JA. Protective effect of BCG vaccination in infant Asians: a case-control study. Arch Dis Child 1988;63:277-81.

3 Lorber J. Freeze dried BCG vaccination of newborn infants by the multiple puncture method. Tubercle 1959:40:21-5.

4 Cundall DB, Pearson SB. Inner city tuberculosis and immunisation policy. Arch Dis Child 1988;63:964-6.

(Accepted 22 fuly 1988
Clinique Néphrologique,

Hôpital Albert Calmette,

50937 Lille Cedex, France

D C Pagniez, MD,

nephrologist

E MacNamara, MD,

nephrologist

F Fortin, MD, pneumologist

L Delvallez, MD, nephrologist

$P$ Dequiedt, MD,

nephrologist

A Tacquet, $\mathrm{MD}$, head of

department

\section{Laboratorie de}

Bactériologie, Hôpital

Albert Calmette

A Fruchart, PHD,

microbiologist

Correspondence to:

Dr Pagniez.

\section{Withdrawal of continuous ambulatory peritoneal dialysis to treat mild peritonitis}

\author{
D C Pagniez, E MacNamara, F Fortin, \\ L Delvallez, A Fruchart, P Dequiedt, A Tacquet
}

To limit admission to hospital and the use of costly or toxic antibiotics we treated patients who developed peritonitis during continuous ambulatory peritoneal dialysis by temporarily interrupting the dialysis, as suggested by Guiberteau et al. ${ }^{1}$ We restricted this method of treatment to generally healthy patients with mild peritonitis.

\section{Patients, methods, and results}

Between 1 June 1986 and 31 July 1987 patients who developed peritonitis at home were treated by temporary interruption of dialysis unless they had one of several contraindications (box). The decision to interrupt dialysis or to use classic treatment was taken on admission purely on clinical grounds. Selected patients had three rapid exchanges of 2 litres without dwell time; if the third bag of effluent was cloudy the patient was not treated by interrupting the dialysis. The catheter was then filled with $500 \mathrm{mg}$ cephalothin in saline, which is necessary to avoid persistence of bacteria, ${ }^{1}$ and closed. No attempt was made to inject cephalothin into the peritoneal cavity, and no systemic antibiotics were given. Patients were discharged and seen again 48 hours later. Two rapid 2 litre exchanges were then given, and dialysis was resumed as usual.

Forty six episodes of peritonitis occurred during the study; 22 episodes in 12 patients were treated by
Contraindications to using temporary interruption of continuous ambulatory peritoneal dialysis to treat peritonitis

- Long delay before referral (>12 hours)

- Fever

- Purulent effluent (and third lavage bag cloudy)

- Obvious infection around the catheter

- Poor general condition (malnutrition)

- Immune suppression

- Recent abdominal surgery (for example, catheter insertion)

- Recent peritonitis ( $<15$ days)

- Abnormal peritoneal cavity (for example, hernia)

- Abnormal peritoneum (for example, asbestosis)

- Disconnect systems for attachment of lavage bags

interruption of dialysis. Initial cell counts in the dialysis fluid ranged from $0 \cdot 13$ to $16 \times 10^{9} / 1$ (mean $28 \times 10^{\circ} / 1$ ) with more than $50 \%$ neutrophils. Interruption of dialysis for 48 hours was well tolerated in all cases. When dialysis was resumed the first lavage bag was often cloudy, but the second bag was clear in all but one patient. Eighteen episodes in 10 patients were cured by interrupting dialysis, and the patients stayed free from peritonitis for at least 15 days without intraperitoneal or systemic antibiotic treatment.

Several organisms were isolated - namely, Staphylococcus epidermidis (four patients), Staph aureus (two), Streptococcus faecalis, and non-groupable streptococcus and Escherichia coli (one each). Three patients with Staph epidermidis peritonitis required conventional antibiotic treatment in the $\mathbf{1 5}$ days after dialysis was interrupted. One had pus in her catheter, which was aspirated, though the lavage bags were clear when dialysis was resumed. The two other patients developed peritonitis again after being free of it for 